\title{
BMJ Open Association between polypharmacy and falls in older adults: a longitudinal study from England
}

\author{
Nafeesa N Dhalwani, ${ }^{1}$ Radia Fahami, ${ }^{1}$ Harini Sathanapally, ${ }^{1}$ Sam Seidu, ${ }^{1}$ \\ Melanie J Davies, ${ }^{1,2}$ Kamlesh Khunti ${ }^{1}$
}

To cite: Dhalwani NN, Fahami R, Sathanapally $\mathrm{H}$, et al. Association between polypharmacy and falls in older adults: a longitudinal study from England. BMJ Open 2017;7:e016358. doi:10.1136/ bmjopen-2017-016358

- Prepublication history for this paper is available online. To view these files, please visit the journal online (http://dx.doi. org/10.1136/bmjopen-2017016358).

Received 8 February 2017 Revised 10 August 2017 Accepted 29 August 2017

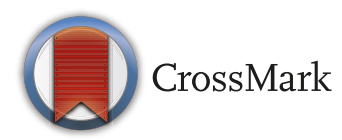

${ }^{1}$ Department of Diabetes Research Centre, University of Leicester, Leicester Diabetes Centre, Leicester General Hospital, Leicester, UK

${ }^{2}$ Leicester Biomedical Research Centre, Leicester, UK

Correspondence to Dr Nafeesa N Dhalwani; nnd2@le.ac.uk

\section{ABSTRACT}

Objectives Assess the longitudinal association between polypharmacy and falls and examine the differences in this association by different thresholds for polypharmacy definitions in a nationally representative sample of adults aged over 60 years from England.

Design Longitudinal cohort study.

Setting The English Longitudinal Study of Ageing waves 6 and 7.

Participants 5213 adults aged 60 or older.

Main outcome measures Rates, incidence rate ratio

(IRR) and $95 \% \mathrm{Cl}$ for falls in people with and without polypharmacy.

Results A total of 5213 participants contributed 10502 person-years of follow-up, with a median follow-up of 2.02 years (IQR 1.9-2.1 years). Of the 1611 participants with polypharmacy, 569 reported at least one fall within the past 2 years (rate: 175 per 1000 person-years, $95 \% \mathrm{Cl} 161$ to 190 ), and of the 3602 participants without polypharmacy 875 reported at least one fall (rate: 121 per 1000 person-years, $95 \% \mathrm{Cl} 113$ to 129 ). The rate of falls was $21 \%$ higher in people with polypharmacy compared with people without polypharmacy (adjusted IRR 1.21, $95 \% \mathrm{Cl} 1.11$ to 1.31 ). Using $\geq 4$ drugs threshold the rate of falls was $18 \%$ higher in people with polypharmacy compared with people without (adjusted IRR 1.18, $95 \% \mathrm{Cl} 1.08$ to 1.28 ), whereas using $\geq 10$ drugs threshold polypharmacy was associated with a $50 \%$ higher rate of falls (adjusted IRR $1.50,95 \% \mathrm{Cl} 1.34$ to 1.67 ).

Conclusions We found almost one-third of the total population using five or more drugs, which was significantly associated with $21 \%$ increased rate of falls over a 2-year period. Further exploration of the effects of these complex drug combinations in the real world with a detailed standardised assessment of polypharmacy is greatly required along with pragmatic studies in primary care, which will help inform whether the threshold for a detailed medication review should be lowered.

\section{INTRODUCTION}

With the changing demographics and an increase in the older population in the last few decades, multimorbidity has become an important public health issue globally. The rising prevalence of multimorbidity ${ }^{1}$ leads to the application of multiple disease-specific guidelines and targeting disease-specific

\section{Strengths and limitations of this study}

- To our knowledge this is one of the largest population-based longitudinal studies to assess the association between polypharmacy and falls in England, including over 5000 participants.

- Data collected on medication use were self-reported and the nurse interviewers were asked to see the containers for all the medications being taken as an added check to verify the medications; therefore, the assessment of drug use was robust and more likely to capture patients' actual medication use than prescribing or dispensing data.

- Data on falls were collected through retrospective self-reports; therefore, there may be some misclassification in the reporting of falls in the study.

- We used longitudinal data to minimise the potential for reverse causality and adjusted for multimorbidity to minimise confounding-by-indication; however, the potential of residual confounding cannot be completely eliminated.

goals. This consequently results in high treatment burden and polypharmacy (defined as the chronic coprescription of multiple drugs). According to the Prescribing Cost Analysis in England, the total number of items dispensed in England in the year 2015 was 1.08 billion, which corresponds to $\sim 19.9$ medications per patient ${ }^{2}$ compared with 962 million in 2011 ( 18.3 medications per patient). ${ }^{3}$ Polypharmacy has been associated with an increased risk of hospitalisation, ${ }^{4}$ functional decline ${ }^{5}$ cognitive impairment, ${ }^{6} 7$ non-adherence, ${ }^{8}$ adverse drug reactions ${ }^{9}$ and drug-drug interactions $^{10}{ }^{11}$ (ie, escalation or suppression of the effects of a drug in the presence of another drug), which further escalate the risk of hospitalisation. ${ }^{12}$

Falls can cause serious injuries and are associated with considerable morbidity and mortality, especially in the elderly. It has been estimated that $5 \%$ of falls result in fractures, and fall-induced injuries are the fifth leading cause of death in elderly adults, accounting 
for over $80 \%$ of injury-related admissions to hospital of people older than 65 years ${ }^{13}$ and costing the National Health Service (NHS) and social care around £6 million per day or £2.3 billion per year. ${ }^{14}$ Data from the USA report the costs to be about $\$ 20$ billion. ${ }^{15}$ Previous studies have predominantly found an association between polypharmacy and falls, ${ }^{16-22}$ with some studies reporting no association. ${ }^{23-26}$ Most of these studies have mainly been limited by the small sample sizes, ${ }^{192122} 25$ selective study populations, ${ }^{1926}$ inadequate adjustments for confounders ${ }^{18}$ or cross-sectional analyses, making them subject to reverse causation. ${ }^{18}$ Furthermore, there is no standardised definition of polypharmacy, making it difficult to interpret the results and translate these into clinical guidelines. The new guidelines on the management of multimorbidity by the National Institute for Health and Care Excellence have made some recommendations to tackle polypharmacy; however, these guidelines mainly focus on patients with $10-14$ prescribed medications. ${ }^{27}$ Nevertheless, risks for adverse events like falls may be high even in patients prescribed lower than 10 drugs. ${ }^{16}$ Therefore, we aimed to assess the association between polypharmacy and falls within 2 years of polypharmacy, in a nationally representative sample of older adults from England, and examine the differences in this association by different thresholds for polypharmacy definitions.

\section{METHODS}

\section{Data source and study population}

The English Longitudinal Study of Ageing (ELSA) is an ongoing study of a nationally representative sample of the English population aged $\geq 50$ years. Participants were recruited from households that were included in the Health Survey for England in 1998, 1999 and 2001, and then followed up every 2 years with detailed health examinations through nurse visits taking place every 4 years. ${ }^{28}$ ELSA has been shown to be broadly representative of the English population in terms of sociodemographics. ${ }^{28}$ In order to maintain the representation of people between 50 and 53 years, refreshment samples were added at waves 3,4 and 6 . The total number of core members interviewed at wave 6 was $9169 .^{29}$ Ethical approval for ELSA was obtained from NHS Research Ethics Committees under the National Research and Ethics Service, and participants gave full informed written consent for participation. ${ }^{30}$ The study population included all core ELSA participants from wave $6(2012 / 2013)$ aged $\geq 60$ years, included in the nurse visit (as drug and polypharmacy information was only collected in wave 6 , as part of the nurse assessment and data on falls were only collected in people over the age of 60) and follow-up data available in wave $7(2015 / 2016)$.

\section{Exposure}

During the nurse visit at wave 6 , respondents were asked to name all the drugs (including syrups, pills, ointments, puffs) prescribed to them by a nurse or a doctor.
Participants with cognitive or physical impairments were eligible for a proxy interview, to ensure optimal accuracy of the information. For each medication participants were asked if they have taken it in the last 7 days. The name of each medication was recorded by the nurse and a code was attributed to the medication according to the British National Formulary (BNF) V.61, the pharmaceutical reference book in the UK with information and indications, doses, interactions, contraindications and so on for drugs, with a specific chapter on drugs related to various systems in the body, for example central nervous system, cardiovascular and so on. ${ }^{31}$ To verify self-reported medication use, the nurse interviewers checked the containers for all medications reported. ${ }^{32}$ Codes were recorded in a six-digit format reflecting three levels of classification in the BNF, using a leading zero where appropriate (eg, drug in BNF section 10.1.1 coded as 100101). ${ }^{29}$ Devices that do not actually deliver drugs (such as blood glucose monitoring equipment), dressings, stoma, or urinary catheter-related products and vaccines were excluded. In light of a lack of any standard definition of polypharmacy, we used various cut-offs previously used to define polypharmacy (from $\geq 4$ to $\geq 10$ drugs). ${ }^{33}$

\section{Outcome}

During the interview in wave 7 , participants were asked if they had fallen down in the last 2 years, and if yes, then the number of times they had fallen down. People who reported more than 50 falls in 2 years were excluded.

\section{Other covariates}

We also extracted data on other sociodemographic, lifestyle and medical covariates, recorded at wave 6 , that may potentially confound the associations between polypharmacy and falls. These included age, sex, ethnicity (white, non-white and missing), total non-pension net wealth in quintile as a proxy measurement of socioeconomic status, lifestyle factors including smoking (smoker, non-smoker), excess alcohol consumption (defined as $\geq 4$ alcohol units/ day for men and $\geq 3$ alcohol units/day for women), body mass index (measured at the nurse visit and categorised as underweight $\left(<18.5 \mathrm{~kg} / \mathrm{m}^{2}\right)$, normal $(\geq 18.5 \mathrm{~kg} /$ $\left.\mathrm{m}^{2}-24.9 \mathrm{~kg} / \mathrm{m}^{2}\right)$, overweight $\left(\geq 25.0 \mathrm{~kg} / \mathrm{m}^{2}-29.9 \mathrm{~kg} / \mathrm{m}^{2}\right)$, obese $\left(\geq 30 \mathrm{~kg} / \mathrm{m}^{2}\right.$ ) and missing), walking speed (as a proxy measure of physical disability) and multimorbidity (defined as two or more conditions of the 18 conditions recorded in ELSA, including diabetes, hypertension, stroke, myocardial infarction, congestive heart failure, angina, lung disease, chronic obstructive pulmonary disease, asthma, arthritis, osteoporosis, cancer, hearing problems, Parkinson's, Alzheimer's disease, dementia, macular degeneration and glaucoma). ${ }^{34}$

\section{Statistical analysis}

We first summarised the population characteristics using means (SD), median (IQR) and proportions by whether the participants had reported a fall in the subsequent wave. We calculated the rate of falls by polypharmacy and 
calculated incidence rate ratio (IRR) with 95\% CIs using Poisson regression and adjusting for participant characteristics including age, sex, ethnicity, wealth quintiles, walking speed, smoking status, excess alcohol consumption and multimorbidity. We tested for interaction by patient characteristics including age, sex and walking speed. We then changed the definition of polypharmacy using various thresholds from $\geq 4$ drugs to $\geq 10$ drugs and recalculated the rate of falls and the IRR $(95 \% \mathrm{CI})$ using the same methods as above. All analyses were conducted in Stata V.13 MP.

\section{Patient involvement}

This study used freely available secondary data (ELSA), and no direct patient involvement or engagement took place as part of the study.

\section{RESULTS}

A total of 5213 participants provided data in both waves 6 and 7 with information on polypharmacy and falls. The median age of the participants was 69 years (IQR 64-76), with 2888 (55\%) being female and 5090 (97.6\%) being white. Approximately one-third of the participants belonged to the two poorest quintiles of non-pension wealth. A total of $2444(46.9 \%)$ participants had multimorbidity, with $494(9.5 \%)$ being smokers and 1509 (28.9\%) participants drinking alcohol above the national recommended limit. Of the total study population, 2147 (41.2\%) were overweight and $1563(30 \%)$ were obese.

A total of 1053 (20.2\%) participants used no drugs, 685 (13.1\%) used a single drug, $693(13.3 \%)$ used two drugs, while $279(5.3 \%)$ used 10 or more drugs (figure 1). Of the 4160 participants using one or more drugs, the most common drug classes were cardiovascular (75.0\%), central nervous system (34.9\%) and gastroenterology $(32.5 \%)$, followed by endocrine $(29.6 \%)$ and respiratory $(18.2 \%)$ drugs. Participants with polypharmacy $(\geq 5$ drugs) were slightly older than participants without polypharmacy (median age: 73 years, IQR $67-78$ years; and median age: 68 years, IQR $64-74$ years, respectively). The proportion of women and white participants was very similar in both groups. Of the people with polypharmacy, $10.9 \%$ smoked compared with $8.8 \%$ of people without



Figure 1 Proportion of participants by number of drugs. polypharmacy; however, the proportion of participants consuming excess alcohol was lower in the polypharmacy group compared with the group without polypharmacy; $82.1 \%$ of the people in the polypharmacy group had multimorbidity compared with $31.1 \%$ in the group without. There was a higher proportion of obesity in the polypharmacy group compared with people without polypharmacy ( $41 \%$ vs $25 \%$ ). There was also a gradient by socioeconomic status such that $22.3 \%$ of participants in the polypharmacy group belonged to the poorest quintile compared with $10.9 \%$ in the group without polypharmacy. A similar gradient was seen in walking speed, with $38.2 \%$ participants in the polypharmacy group in the slowest quartile compared with $16.2 \%$ in the group without polypharmacy (table 1). A total of $13.4 \%$ participants in the polypharmacy group has missing data on walking pace compared with $5.4 \%$ in the group without polypharmacy.

A total of 5213 participants contributed 10502 personyears of follow-up, with a median follow-up of 2.02 years (IQR 1.9-2.1 years). Of the 1611 participants with polypharmacy, $569(35.3 \%)$ reported at least one fall within the past 2 years, and of the 3602 participants without polypharmacy $875(24.3 \%)$ reported at least one fall within the past 2 years. In people with polypharmacy the rate of falls was 175 per 1000 person-years (95\% CI 161 to 190 per 1000 person-years) compared with 121 per 1000 person-years (95\% CI 113 to 129 per 1000 personyears) in people without polypharmacy. The unadjusted IRR for fall in people with polypharmacy compared with people without polypharmacy was 1.96 (95\% CI 1.83 to 2.10). After adjusting for sociodemographic, medical and lifestyle factors, the rate of falls was $21 \%$ higher in people with polypharmacy compared with people without polypharmacy (IRR $1.21,95 \%$ CI 1.11 to 1.31 ) (figure 2). There was no significant interaction by age $(p=0.296)$ and sex (0.260); however, there was a significant interaction by walking speed $(\mathrm{p}<0.001)$ such that in people with the fastest and the slowest walking speed quartile there was no statistically significant association between polypharmacy and falls (IRR $0.99,95 \%$ CI 0.75 to 1.30 ; and IRR $1.00,95 \%$ CI 0.88 to 1.13 , respectively); however, there was around a $30 \%$ increase in the rate of falls associated with polypharmacy in the two middle quartiles of walking (IRR 1.31, 95\% CI 1.03 to 1.66 ; and IRR $1.29,95 \%$ CI 1.06 to 1.56 , respectively). In people with missing walking pace, polypharmacy was associated with $90 \%$ increased risk of falls (IRR $1.90,95 \%$ CI 1.54 to 2.36) (figure 3).

When using different thresholds to define polypharmacy, we found that using $\geq 4$ drugs threshold and adjusting for sociodemographic, medical and lifestyle factors, the rate of falls was $18 \%$ higher in people with polypharmacy compared with people without (IRR 1.18, $95 \%$ CI 1.08 to 1.28 ), whereas using $\geq 10$ drugs threshold polypharmacy was associated with a $50 \%$ higher rate of falls (IRR $1.50,95 \%$ CI 1.34 to 1.67) (figure 2). 
Table 1 Characteristics of the study population with and without polypharmacy

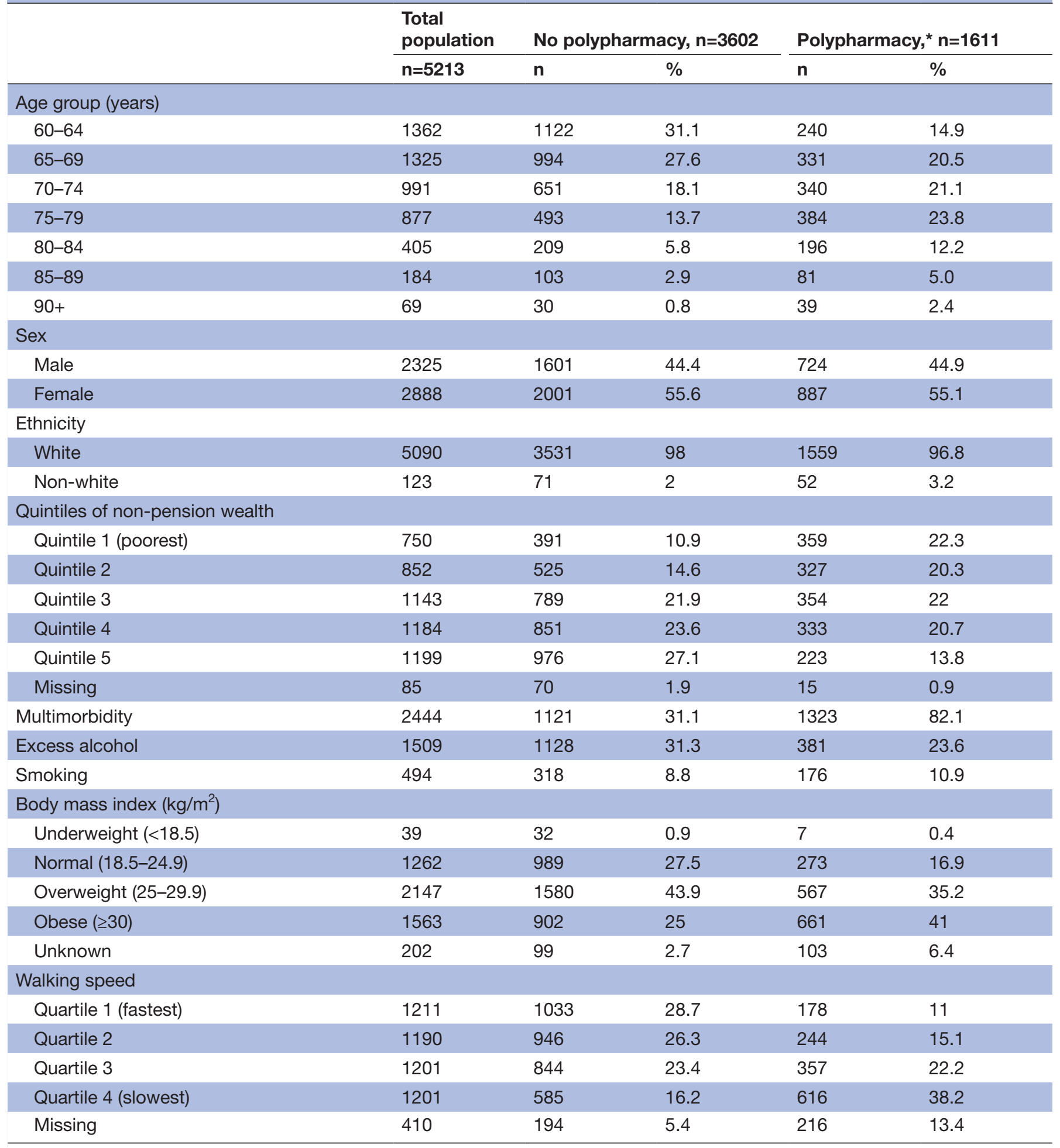

${ }^{*} \geq 5$ drugs.

\section{DISCUSSION}

\section{Principal findings}

In this large, prospective, population-based cohort of older English population, we found the prevalence of polypharmacy to be $30.9 \%$ and $21 \%$ higher rate of falls in people with polypharmacy (IRR 1.21, 95\% CI 1.11 to 1.31 ). The rate of falls in people with polypharmacy was still $18 \%$ higher when using a lower threshold ( $\geq 4$ drugs) (IRR 1.18, 1.08-1.28) and was $50 \%$ higher compared with people without polypharmacy, when using a threshold of $\geq 10$ drugs.

\section{Comparison to current literature}

Comparisons with other studies are challenging due to method of assessment (self-reported vs administrative 


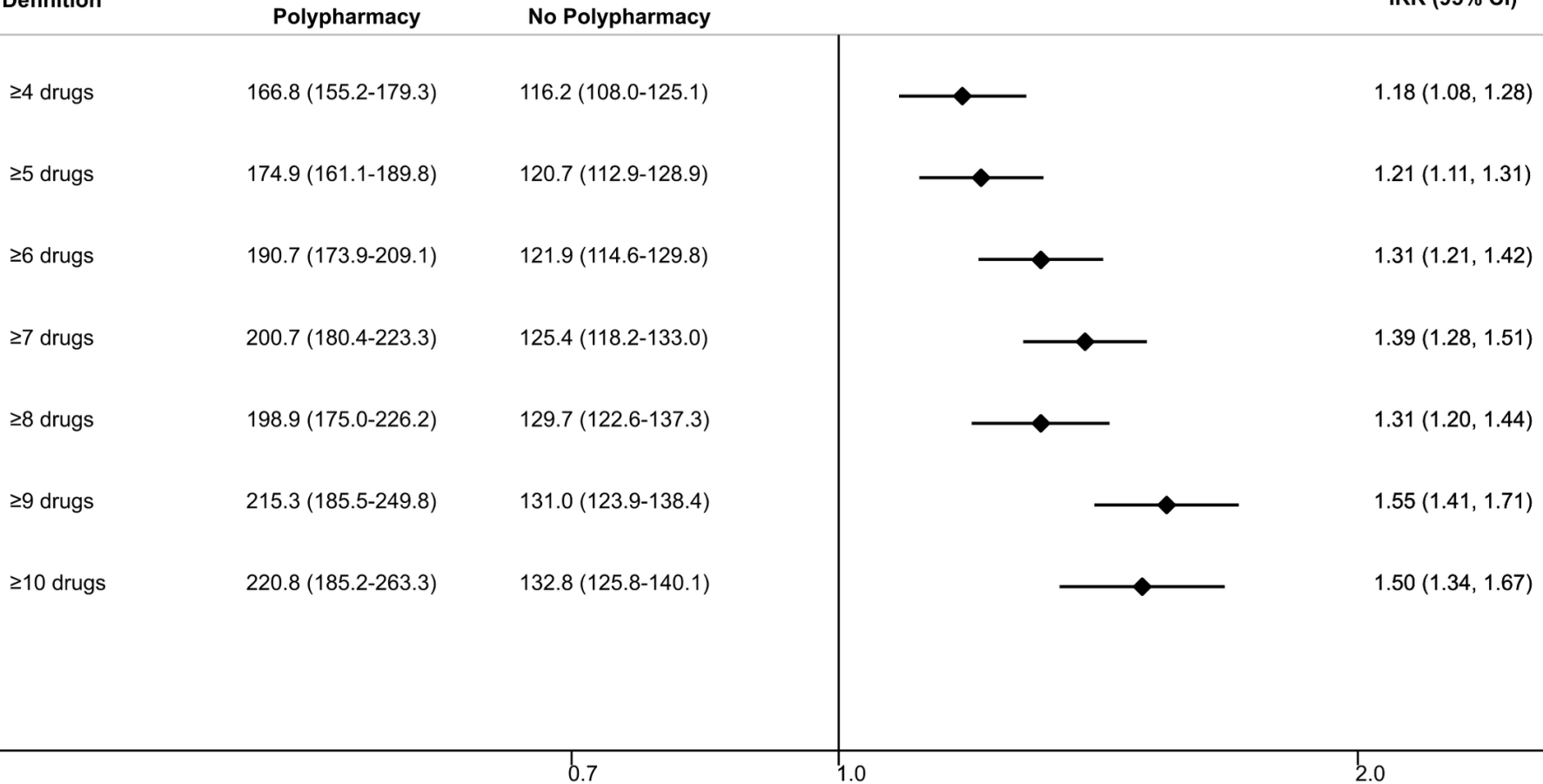

IRR adjusted for age, sex, ethnicity, wealth quintiles, walking speed, smoking status, excess alcohol consumption and multimorbidity

Figure 2 Rates and rate ratios for falls comparing people with and without polypharmacy, using different definitions of polypharmacy. IRR, incidence rate ratio.

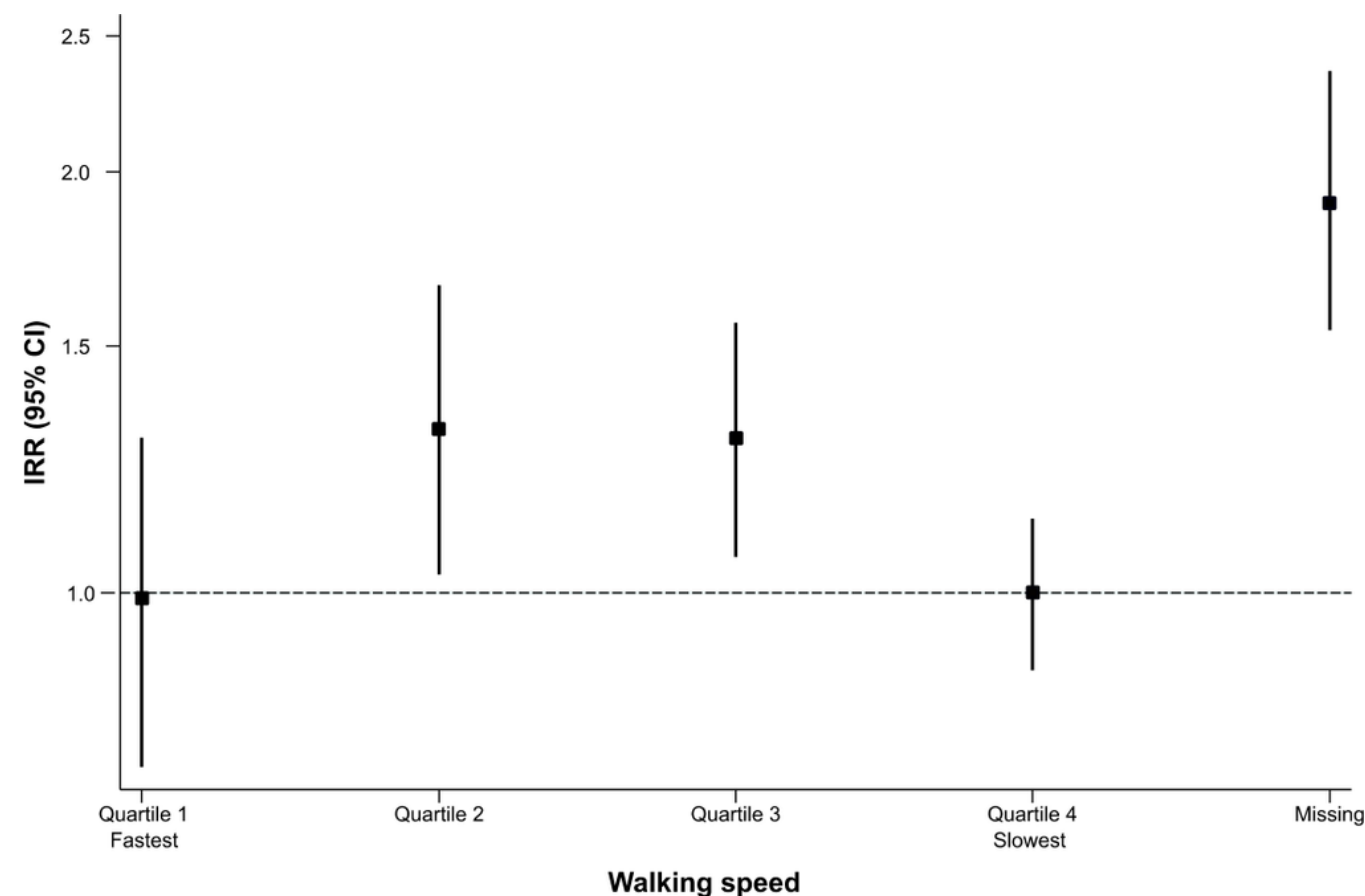

Adjusted for adjusted for age, sex, ethnicity, wealth quintiles, smoking status, excess alcohol consumption and multimorbidity

Figure 3 Rate ratio $(95 \% \mathrm{Cl})$ for falls in association with polypharmacy by each category of walking speed. IRR, incidence rate ratio.

data), baseline populations (all adults vs over $65 \mathrm{~s}$ vs over 80 s), definition of polypharmacy and study settings (care homes vs hospitals vs community). This is further complicated by the differences in demographic compositions of different countries and the healthcare systems. For example, a study based on the Irish pharmacy claims data in individuals over 65 years of age found the prevalence of polypharmacy ( $\geq 5$ drugs) to be $60.4 \%$ in 2012 , which 
was almost double the prevalence in our study. ${ }^{35}$ A potential explanation for this difference on top of the slightly different age cut-off could be that individuals from less affluent socioeconomic groups, female and younger and older populations were slightly over-represented in this study, slightly inflating the overall prevalence of polypharmacy. In contrast, data from the Belgian Health Interview Survey from 2008 found the prevalence of polypharmacy ( $\geq 9$ drugs) to be $33 \%{ }^{36}$ A study from Tayside, Scotland, using a similar population, found the prevalence of polypharmacy ( $\geq 5$ drugs) to be $20.5 \%$ in 2010 , which is still $10 \%$ lower than what we found in our study. ${ }^{37}$ Our estimates are inevitably higher as they included all adults over 20 years of age, whereas our estimates are only based on people over the age of 60 .

In our study, $35.3 \%$ of participants with polypharmacy reported a fall within 2 years. Results from the Rotterdam study show the prevalence of falls to be $16.5 \%$, which is a lot lower than our estimate. ${ }^{17}$ However, $37 \%$ of their study population was younger than 65 years, and the window to assess falls was 1 year compared with 2 years in our study, which may explain the difference in the absolute risk. Nevertheless, the increase in falls by age was consistent with our study. We found the rate of falls to be $21 \%$ higher in people with polypharmacy. This is slightly lower than the results of a cross-sectional analysis from the Stockholm Public Health Cohort, which found the odds of a fall injury in people taking five or more drugs to be $53 \%$ higher than in people taking no drugs (OR $1.53,95 \%$ CI 1.06 to 2.21$).{ }^{20}$ This could potentially be due to the slightly older population in the Swedish cohort and slightly different outcome definition (fall injuries resulting in hospitalisation vs self-reported falls). A recent longitudinal study using The Irish Longitudinal Study of Ageing, including people $\geq 50$, found a non-significant $10 \%$ increase in the rate of falls in people with polypharmacy compared with people without polypharmacy (RR $1.10,95 \%$ CI $0.93,1.30)$; however, this could be due to the slightly wider age group, compared with our study. Nevertheless, when polypharmacy included an antidepressant drug, the rate of falls was $28 \%$ higher in people with polypharmacy compared with people without polypharmacy (1.28, 95\% CI 1.06 to 1.54$)$.

We found a significant interaction by walking speed in the association between polypharmacy and falls such that people in the fastest and slowest walking speed quartiles did not have a significant association between polypharmacy and falls. This may mean that the number of drugs does not increase the risk of falls in the presence of good physical function. This implies that walking speed can be used to triage patients who may need more tailored management of polypharmacy. One potential explanation for the absence of an association in the slowest quartile of walking speed may be that they are not mobile enough to have a fall. However, the absence of an association between polypharmacy and falls in people with slow walking speed needs further investigation.

\section{Strengths and limitations}

To our knowledge this is one of the largest population-based longitudinal studies to assess the association between polypharmacy and falls, including over 5000 participants. ELSA has been shown to be broadly representative of the English population, and therefore findings are generalisable to wider group of older adults in the UK. All participants for wave 6 , however, did not participate in the nurse visit due to different reasons. The response rate for the nurse visit was still as high as $83 \%^{38}$; however, there were slight differences between the participants who completed nurse visit versus participants who did not complete a nurse visit. Participants who completed a nurse visit were on average 1.32 years younger and richer compared with ELSA participants who did not complete a nurse visit. Therefore, we may have slightly underestimated the true prevalence of polypharmacy. Data collected on medication use were self-reported as opposed to a prescription or dispensing database. However, these databases would not account for any over-the-counter or off-the-shelf medications taken or actual use of medication as they only contain information on prescribing or dispensing. In contrast, the nurse interviews in ELSA covered all medications, including all overthe-counter and off-the-shelf medications. Additionally, the nurse interviewers were also asked to see the containers for all the medications, ${ }^{32}$ being taken as an added check to verify the medications. Therefore, we believe that the assessment of drug use, although self-reported, was robust. Data on falls were collected through retrospective self-reports, making it prone to some misclassification. A study comparing retrospective self-report of falls with prospective records in older women from Brazil found moderate agreement (kappa $=0.595)$ with sensitivity and specificity of $67.2 \%$ and $94.2 \%$, respectively. ${ }^{39}$ In comparison, a study comparing retrospective self-reports of falls with prospective calendar-reported method following a randomised controlled trial found $84 \%$ agreement between the two measures; however, the sensitivity was still $56 \% .{ }^{40}$ Information on confounders was extracted at wave 6 , and changes in these covariates over the 2 years were not accounted for in the analysis. We used longitudinal data to minimise the potential for reverse causality and adjusted for multimorbidity to minimise confounding-by-indication; however, the potential of residual confounding cannot be completely eliminated.

\section{CONCLUSION}

We found almost one-third of the total population using five or more drugs, which was significantly associated with $21 \%$ increased rate of falls over a 2-year period. This has important clinical implications because the target group for medication reviews and multimorbidity management, which is currently restricted to individuals with 10 or more drug prescriptions, may miss individuals who are still at a high risk of falls. Therefore, the target patient group may need widening. Further exploration of the effects of these complex drug combinations in the real world with 
a detailed standardised assessment of polypharmacy is greatly required along with pragmatic studies in primary care, which will help inform whether the threshold for a detailed medication review should be lowered. What is also required is a multidisciplinary approach with primary care physicians, specialists and pharmacists working together to minimise harm and optimise drug treatments in this population.

Acknowledgements The authors acknowledge support from the National Institute for Health Research Collaboration for Leadership in Applied Health Research and Care - East Midlands (NIHR CLAHRC - EM), and the NIHR Leicester-Loughborough Diet, Lifestyle and Physical Activity Biomedical Research Unit, which is a partnership between University Hospitals of Leicester NHS Trust, Loughborough University and the University of Leicester. The views expressed are those of the authors and not necessarily those of the NHS, the NIHR or the Department of Health.

Contributors ND conceived and designed the study, acquired the data, carried out statistical analyses, interpreted the results and drafted the manuscript. RF interpreted the results and drafted and revised parts of the manuscript. HS acquired and managed the data and reviewed the manuscript for critical revisions. SS reviewed the manuscript for critical revisions. MJD reviewed the manuscript for critical revisions. KK conceived the idea of the study, designed the study, provided input in the interpretation of findings and reviewed the manuscript. All authors have approved the final manuscript as submitted.

Funding This research received no specific grant from any funding agency in the public, commercial or not-for-profit sectors.

Competing interests KK has acted as a consultant and speaker for Novartis, Novo Nordisk, Sanofi-Aventis, Lilly and Merck Sharp \& Dohme. He has received grants in support of investigator and investigator-initiated trials from Novartis, Novo Nordisk, Sanofi-Aventis, Lilly, Pfizer, Boehringer Ingelheim and Merck Sharp \& Dohme. KK has received funds for research, honoraria for speaking at meetings and has served on advisory boards for Lilly, Sanofi-Aventis, Merck Sharp \& Dohme and Novo Nordisk. MJD has acted as consultant, advisory board member and speaker for Novo Nordisk, Sanofi-Aventis, Lilly, Merck Sharp \& Dohme, Boehringer Ingelheim, AstraZeneca and Janssen, and as a speaker for Mitsubishi Tanabe Pharma Corporation. She has received grants in support of investigator and investigatorinitiated trials from Novo Nordisk, Sanofi-Aventis and Lilly.

Patient consent The study uses secondary data from ELSA available publicly. All participants gave full informed written consent for participation in the study

Ethics approval Ethical approval for ELSA was obtained from NHS Research Ethics Committees under the National Research and Ethics Service (NRES), and participants gave full informed written consent for participation.

Provenance and peer review Not commissioned; externally peer reviewed.

Data sharing statement № additional data are available. However, ELSA can be freely accessed through the UK Data Archive.

Open Access This is an Open Access article distributed in accordance with the Creative Commons Attribution Non Commercial (CC BY-NC 4.0) license, which permits others to distribute, remix, adapt, build upon this work non-commercially, and license their derivative works on different terms, provided the original work is properly cited and the use is non-commercial. See: http://creativecommons.org/ licenses/by-nc/4.0/

(C) Article author(s) (or their employer(s) unless otherwise stated in the text of the article) 2017. All rights reserved. No commercial use is permitted unless otherwise expressly granted.

\section{REFERENCES}

1. Dhalwani NN, O'Donovan G, Zaccardi F, et al. Long terms trends of multimorbidity and association with physical activity in older English population. Int J Behav Nutr Phys Act 2016;13:8.

2. The NHS Health \& Social Care Information Centre. Prescription Cost Analysis England 2015. Leeds: NHS Health And Social Care Information Centre, 2016.

3. The NHS Health \& Social Care Information Centre. Prescription Cost Analysis - England 2011. Leeds: The NHS Health \& Social Care Information Centre, 2012.
4. Akazawa M, Imai $\mathrm{H}$, Igarashi $\mathrm{A}$, et al. Potentially inappropriate medication use in elderly Japanese patients. Am J Geriatr Pharmacother 2010;8:146-60.

5. Rosso AL, Eaton CB, Wallace R, et al. Geriatric syndromes and incident disability in older women: results from the women's health initiative observational study. J Am Geriatr Soc 2013;61:371-9.

6. Jyrkkä J, Enlund H, Lavikainen P, et al. Association of polypharmacy with nutritional status, functional ability and cognitive capacity over a three-year period in an elderly population. Pharmacoepidemiol Drug Saf 2011;20:514-22.

7. Martin NJ, Stones MJ, Young JE, et al. Development of delirium: a prospective cohort study in a community hospital. Int Psychogeriatr 2000;12:117-27.

8. Salazar JA, Poon I, Nair M. Clinical consequences of polypharmacy in elderly: expect the unexpected, think the unthinkable. Expert Opin Drug Saf 2007;6:695-704.

9. Bourgeois FT, Shannon MW, Valim C, et al. Adverse drug events in the outpatient setting: an 11-year national analysis. Pharmacoepidemiol Drug Saf 2010;19:901-10.

10. Mallet L, Spinewine A, Huang A. Prescribing in elderly people 2 - the challenge of managing drug interactions in elderly people. Lancet 2007;370:185-91.

11. Björkman IK, Fastbom J, Schmidt IK, et al.Drug-drug interactions in the elderly. Ann Pharmacother 2002;36:1675-81.

12. Gurwitz JH, Field TS, Harrold LR, et al. Incidence and preventability of adverse drug events among older persons in the ambulatory setting. JAMA 2003;289:1107-16.

13. Kannus P, Parkkari J, Niemi S, et al. Fall-induced deaths among elderly people. Am J Public Health 2005;95:422-4.

14. Age UK. Stop Falling: start saving lives and money. Age UK 2010.

15. Stevens JA, Corso PS, Finkelstein EA, et al. The costs of fatal and non-fatal falls among older adults. Inj Prev 2006;12:290-5.

16. Zia A, Kamaruzzaman SB, Tan MP. Polypharmacy and falls in older people: balancing evidence-based medicine against falls risk. Postgrad Med 2015;127:330-7.

17. Ziere G, Dieleman JP, Hofman A, et al. Polypharmacy and falls in the middle age and elderly population. Br J Clin Pharmacol 2006;61:218-23.

18. Wong $\mathrm{H}$, Heuberger R, Logomarsino J, et al. Associations between alcohol use, polypharmacy and falls in older adults: helen wong and colleagues report on a cross-sectional study into alcohol consumption, medication use and falls in the community. Nursing older people 2016;28:30-6.

19. Baranzini F, Diurni M, Ceccon F, et al. Fall-related injuries in a nursing home setting: is polypharmacy a risk factor? BMC Health Serv Res 2009;9:228

20. Helgadottir B, Laflamme L, Monarrez-Espino J, et al. Medication and fall injury in the elderly population; do individual demographics, health status and lifestyle matter?. Bmc Geriatr 2014;14.

21. Kojima T, Akishita M, Nakamura T, et al. Association of polypharmacy with fall risk among geriatric outpatients. Geriatr Gerontol Int 2011;11:438-44.

22. Kojima T, Akishita M, Nakamura T, et al. Polypharmacy as a risk for fall occurrence in geriatric outpatients. Geriatr Gerontol Int 2012;12:425-30.

23. Tromp AM, Pluijm SM, Smit JH, et al. Fall-risk screening test: a prospective study on predictors for falls in community-dwelling elderly. J Clin Epidemiol 2001;54:837-44.

24. Zia A, Kamaruzzaman SB, Tan MP. The consumption of two or more fall risk-increasing drugs rather than polypharmacy is associated with falls. Geriatr Gerontol Int 2017;17:463-70.

25. Weber V, White A, Mcllvried R. An electronic medical record (EMR)-based intervention to reduce polypharmacy and falls in an ambulatory rural elderly population. J Gen Intern Med 2008;23:399-404.

26. Lawlor DA, Patel R, Ebrahim S. Association between falls in elderly women and chronic diseases and drug use: cross sectional study. BMJ 2003;327:712-7.

27. Farmer C, Fenu E, O'Flynn N, et al. Clinical assessment and management of multimorbidity: summary of NICE guidance. BMJ 2016;354:i4843.

28. Steptoe A, Breeze E, Banks J, et al. Cohort profile: the English longitudinal study of ageing. Int J Epidemiol 2013;42:1640-8.

29. Banks J, Nazroo J, Steptoe A. The dynamics of ageing: evidence from the english longitudinal study of ageing 2002-12 (wave 6). London: The Institute for Fiscal Studies 2014

30. NatCen Social Research. English Longitudinal Study of Ageing (ELSA) wave 1 to wave 6- user guide to the core datasets. 2014. http://doc.ukdataservice.ac.uk/doc/5050/mrdoc/pdf/5050_ELSA_ User_Guide_Waves_1-6_v1.pdf (Accessed 15 Mar 2015). 
31. Joint Formulary Committee. British National Formulary (BNF) 61st ed. London: BMJ Group and Pharmaceutical Press, 2011.

32. NatCen Social Research. English Longitudinal Study of Ageing (ELSA) - Wave 6 nurse questionnaire. London: NatCen Social Research, 2014.

33. Hammond T, Wilson A. Polypharmacy and falls in the elderly: a literature review. Nurs Midwifery Stud 2013;2:171-5.

34. Dhalwani NN, Zaccardi F, O'Donovan G, et al. Association between lifestyle factors and the incidence of multimorbidity in an older english population. J Gerontol A Biol Sci Med Sci 2016: glw146.

35. Moriarty F, Hardy C, Bennett K, et al. Trends and interaction of polypharmacy and potentially inappropriate prescribing in primary care over 15 years in Ireland: a repeated cross-sectional study. BMJ Open 2015;5:e008656.
36. Walckiers D, Van der Heyden J, Tafforeau J. Factors associated with excessive polypharmacy in older people. Arch Public Health 2015;73:50.

37. Guthrie B, Makubate B, Hernandez-Santiago V, et al. The rising tide of polypharmacy and drug-drug interactions: population database analysis 1995-2010. BMC Med 2015;13:74.

38. Bridges S, Hussey D, Blake M. The dynamics of ageing: the 2012 English Longitudinal Study of Ageing (Wave 6). London: NatCen Social Research 2015.

39. Garcia PA, Dias JM, Silva SL, et al. Prospective monitoring and selfreport of previous falls among older women at high risk of falls and fractures: a study of comparison and agreement. Braz J Phys Ther 2015;19:218-26.

40. Mackenzie L, Byles J, D'Este C. Validation of self-reported fall events in intervention studies. Clin Rehabil 2006;20:331-9. 